\title{
Political pressure deflection
}

\author{
James E. Anderson • Maurizio Zanardi
}

Received: 20 December 2006 / Accepted: 7 April 2009 / Published online: 21 April 2009

(C) The Author(s) 2009. This article is published with open access at Springerlink.com

\begin{abstract}
Much economic policy is deliberately shifted away from direct political processes to administrative processes - political pressure deflection. Pressure deflection poses a puzzle to standard political economy models which suggest that having policies to 'sell' is valuable to politicians. The puzzle is solved here by showing that incumbents will favor pressure deflection since it can deter viability of a challenger, essentially like entry deterrence. U.S. trade policy since 1934 provides a prime example, especially antidumping law and its evolution.
\end{abstract}

Keywords Pressure deflection · Elections · Antidumping

JEL Classification D72 $\cdot$ F13 $\cdot$ H11

\section{Introduction}

Politicians often appear to avoid taking stands, duck responsibility, hide behind others. Politicians also actively design mechanisms to deflect political pressure. U.S. trade policy is a prime example. Since 1934, the Congress has delegated its constitutional authority over trade policy to the president, periodically renewing the delegation and enhancing its value to protectionists by expanding the role of rules-driven processes such as antidumping. Destler (1995) interprets the delegation of trade policy as pressure deflection, making his case with compelling descriptions of U.S. trade policy history.

Political pressure deflection is an anomaly relative to the current benchmark political economy model. 'Policy for sale' models (Bernheim and Whinston 1986; Grossman and Helpman 1994; Dixit et al. 1997) posit an incumbent politician who auctions policies to

J.E. Anderson

Boston College and NBER, Boston, MA, USA

M. Zanardi (凶)

ECARES, Université Libre de Bruxelles, Brussels, Belgium

e-mail: mzanardi@ulb.ac.be 
interest groups, a clean and plausible structure with empirical support in the pattern of U.S. trade policy (Goldberg and Maggi 1999; Gawande and Bandhopadhyay 2000). Delegation of trade policy is a peculiar anomaly since the Congress prior to 1934 was very actively engaged in policy-for-sale and could obviously do so again. Political economy theory should explain why congressmen continue to give away what they could sell. ${ }^{1}$

This paper provides a necessary first step to a political economy of the persistence of trade policy delegation by providing a model of the demand for deflection. Deflection is a potential defense strategy for at least some congressmen. We do not formally model the legislative process but we argue informally below for thinking of the median congressman as preferring deflection. Deflection as a defense strategy arises because if the incumbent rejects (accepts) an approach from Protectionist lobby $\mathrm{P}$, he is revealed as an enemy to $\mathrm{P}$ (to opposing Liberal lobby L). This revelation may induce the lobbies to confer viability on a challenger who will support their position. By deflecting pressure when deflection is an option, the incumbent avoids revealing his preferences. This lowers the chance that he faces a viable opponent, one able to attract sufficient funding to effectively compete in the election. When the value of deflection is sufficiently large, it dominates the value of being able to sell policy for the individual congressman, and he will support a pressure deflection regime. Deflection is likely to be valued by incumbent congressmen on issues for which most political participants are nearly indifferent, but for which interest groups on each side are willing to lobby in his district. Trade policy fits the description for many congressmen although the argument can be applied to other policy dimensions.

The antidumping system of trade protection when imports are dumped (i.e., foreign producer selling below average variable cost or at price lower than in its home market) can be interpreted as pressure deflection. Thus, we will use it in motivating the analysis. Our setup follows the antidumping rules of the United States and may not be directly applied to other counties. However, we note that the recent wave of adoptions of antidumping laws by many (developing) countries is consistent with the possibility that pressure deflection has an appeal in other countries. An analysis of the country-specific legal provisions is beyond the scope of this paper but may provide further insight since some countries have opted for strictly bureaucratic systems while others allow political involvement.

Our story of the demand for pressure deflection suggests useful empirical predictions about support for the regime but it also presents natural limits. Pressure deflection is useless to an incumbent who cannot escape a quality challenger. Presidential races always have a quality challenger, so the story explains why the president accepts delegation of a 'pressurized policy'. ${ }^{2}$ In contrast, many congressional races are essentially uncontested in the sense that only one candidate (usually the incumbent) is viable, raises much money in a setting where the candidate with more money wins almost always (see for example Anderson and Prusa 2001a). Pressure deflection is also useless when the politician's preferences have been revealed. ${ }^{3}$

Most congressional delegation of power to the executive is driven by sheer necessity. The huge size of government and the limited resources of Congress lead Epstein and O'Halloran

\footnotetext{
${ }^{1}$ Destler (1995) does not show why deflection is in the interest of congressmen.

${ }^{2}$ Alesina and Tabellini (2005) note that trade policy is not delegated by the president to an independent authority, in contrast to the way that monetary policy is delegated to a central bank. All administrative measures under U.S. trade law are ultimately at the discretion of the president following advice from agencies such as the International Trade Commission. Political competition in presidential races is modeled in Grossman and Helpman (1999) as an extension of policy for sale models.

${ }^{3}$ Thus deflection is unlikely on issues for which the incumbent's political faction is a reliable signal of his preferences (e.g., abortion, minimum wage).
} 
(1999) to propose that the Congress's decision to delegate or not is akin to the firm's decision to buy or make. They propose a transaction-cost model of the decision whereby Congress retains policy if issues are not highly technical and redistribution is prominent. If delegation occurs anyway, as for trade policy, pressure deflection may be the explanation. ${ }^{4}$ Pressure deflection complements transaction costs by providing an additional advantage of delegation for an incumbent politician in some situations. Pressure deflection appears decisive in trade policy delegation, but it is likely to play a role for other policies too since the essence of the argument does not hinge on any feature specific to trade policy. Regulatory agencies may play a role similar to the authorities in charge of antidumping.

In the realm of trade policy, Mayer (1999) proposes an alternative rationale for infrequently changed tariff laws combined with delegation to frequently adjusted administrative measures. He treats government as a unitary actor maximizing a political support function. There are benefits to flexibility in the face of shocks to world prices and productivity while there are costs to the exercise of discretionary authority outside the discipline of democratic restraint. In contrast, our paper focuses on multiple political actors and abstracts from benefits of flexibility.

The seminal paper by Finger et al. (1982) provides empirical evidence consistent with our story. They compare the use of antidumping and escape clauses in the United States and show that antidumping is the poor (or small) man's escape clause since only prominent cases are pursued with a petition for an escape clause which requires the president's approval. Instead, smaller cases are handled with the administrative (antidumping) track. This evidence is consistent with the pressure deflection argument whereby lobbies will offer large contributions, which the incumbent will accept, when the political value of a committed politician is high. Conversely, the antidumping system reveals its relevance when the stakes are smaller and politicians prefer not to be drawn into the issue.

In this paper, the decision to deflect is equivalent to hiding policy preferences. Several contributions focus on the optimality of ambiguity given the risk profile of voters. Shepsle (1972) shows that ambiguity pays off only when a majority of voters are risk-loving; otherwise, the median voter result applies with political convergence occurring. Alesina and Cukierman (1990) extend these results to a two-period model where politicians also care about policies. In this case, some degree of ambiguity may be optimal for the candidates even if voters are risk averse. Alternatively, a paper by Aragones and Neeman (2000) focuses on the candidates and shows that they may choose some level of ambiguity during the electoral campaign based on the assumption that policy commitment is costly. Our model departs from these studies in two ways. First, we emphasize the interplay between politicians and lobbies, while voters' behavior is embodied in the function determining the election outcome. Secondly, ambiguity arises endogenously as the optimal strategy in trying to deter challengers to enter the race.

The remainder of the paper is organized as follows. Sect. 2 argues that the delegation of U.S. trade policy-making should be understood as pressure deflection. Section 3 sets up

\footnotetext{
${ }^{4}$ Epstein and O'Halloran (1999) explain delegation of trade policy as due to the excessive costs generated by congressional logrolling. This may help explain the Trade Agreements Act of 1934, when the example of the Smoot-Hawley Tariff of 1930 was fresh, but we find it unconvincing as a continuing explanation for seventy years. Their general rule is that "informationally intense policy areas" will be delegated while "distributive issues" will not. This dichotomy fails to predict trade policy as a highly delegated policy area. Epstein and O'Halloran (1999: 198) recognize this puzzle in their empirical analysis where they refer to trade as a one of "two surprising areas that we see highly delegated ... [although] usually described as quintessential distributive issues.” See Destler (1995) for a description of delegation in U.S. trade policy after 1934 as a pressure deflection system which contradicts the logrolling costs story.
} 
the model while its implications are discussed in Sect. 4. Section 5 informally discusses the emergence and persistence of a deflection regime using the model as a frame of reference. Section 6 analyzes the desirability of deflection to the individual incumbent in more detail with a simulation approach. Section 7 concludes.

\section{Deflection and U.S. trade institutions}

The Reciprocal Trade Agreements Act of 1934 delegated the authority to make reductions in the Smoot-Hawley Tariff of 1930 as a result of bilateral negotiations, a delegation periodically renewed ever since. Tariffs, formerly policies for sale in the Congress, became bargaining chips in international negotiations conducted by the executive. Therefore, narrowly focused interest groups had less incentive to pressure congressmen over details of trade policy decided by the executive. Destler (1995) provides a detailed description of the debate over the Trade Act of 1974 which illustrates his interpretation of trade policy delegation as pressure deflection. Key congressmen preserved trade policy delegation in the face of pressures to take it back because they understood delegation as valuable pressure deflection. Delegation has been further strengthened by fast track procedures (i.e., the president's authority to negotiate trade agreements that can only be approved or rejected by the Congress without amendments) which have been used ever since.

Destler does not question why pressure deflection is valued by incumbents. We show below that deflection has value by allowing the incumbent's trade preferences to be concealed. Revelation is occasionally forced by the necessity of congressional action on a major trade agreement, but the revelation is partial (since the fast track process removes the possibility of advancing a narrow interest through ad hoc amendments); it is especially concentrated and infrequent enough so that deflection retains value. ${ }^{5}$

U.S. antidumping (AD) law makes political economic sense when interpreted as pressure deflection. AD provides an administrative channel to obtain protection against imports that are sold in the United States at a price lower than the one charged in the country where they are produced or below average cost. Also, AD law and its outcomes appear to make no sense for a government which cares about welfare. The predatory competition story which is sometimes offered as a rationale (dumpers will drive out home firms, then raise prices) is inconsistent with the observation that U.S. AD law makes no mention of consumer interests, and also inconsistent with the evidence in many AD cases (Shy 1998). ${ }^{6}$ Still, incumbents can deflect political pressure for protection from narrow interest groups into this channel when it is advantageous to conceal their trade preferences. ${ }^{7}$

Congressional support for AD through several rounds of amendment and greatly expanded use since the early 1980s illustrates how members value this option. AD is by far the most important source of new protectionist policy in the United States over the last 20

\footnotetext{
${ }^{5}$ Even past votes on trade bills may not be very informative. For example, the position of Senator Kennedy in 2000 on the bill granting permanent normal trade relations to China was very uncertain although Senator Kennedy had been in the Senate for almost 40 years at the time of the vote.

${ }^{6}$ Anderson (1993) examined a potential rationale in his 'domino dumping' model on the basis that AD would lower the probability of voluntary export restraints. However, he found it quite fragile, depending on parameter values in a special setting.

${ }^{7}$ Congressional dominance theory suggests that Congress can influence agency decisions. When it comes to $\mathrm{AD}$, various empirical papers have analyzed the decisions of the International Trade Commission, which is in charge of injury determinations in AD cases. The results are mixed with a recent paper by De Vault (2002) concluding that statutory factors are much more relevant than congressional influence.
} 
years, and it accounts for as much distortion as all the other remaining protectionist policies of the United States (Gallaway et al. 1999). Despite pressure from trade liberalizers, AD survived reform efforts during the Uruguay Round and as legitimated by the WTO it is now a standard mechanism around the world. In fact, Zanardi (2004) documents that the number of countries with an AD law almost doubled between 1990 and 2001 and nowadays the use of $\mathrm{AD}$ is not confined only to the traditional users (i.e., Australia, Canada, Europe, United States) and is especially concentrated among developing countries like India, Mexico, and South Africa. Although AD protection is now also targeting producers from the developed world, the United States is firmly against any substantial reform of the AD system. In fact, the Congress's renewal of fast track authority in 2002 came with the insistence that the AD law was not negotiable in the Doha round.

Deflection in principle can involve both import-competing and exporter groups, but in practice it is mostly the former. Though AD is one-sided against imports, Section 301 of the U.S. Trade Law of 1974 can offer an analogous solution to export lobbies since it authorizes executive action against unfair trade practices by foreign countries. While less active than $\mathrm{AD},{ }^{8}$ Section 301 has resulted in significant market opening negotiations, most prominently the Semiconductor Agreement between the United States and Japan. Finally, we note that the negotiation of small scale free trade agreements, such as the one with Jordan, may also offer a safety valve for narrowly based exporter interest pressures which complements the delegation of trade policy to the executive. These facts suggest that Congress understands the pressure deflection value of delegation and the safety-valve role of AD and possibly of Section 301 and of bilateral free trade negotiations. We exemplify pressure deflection as AD below for simplicity.

\section{The model}

We first introduce the model in an intuitive way. It builds on the political competition model of Baron (1989) as extended by Anderson and Prusa (2001a) to explain uncontested races. An incumbent politician and a challenger run for office pursuing an electoral strategy that develops into two stages. Both the incumbent and the challenger gain utility by holding office and by advocating their preferred (and unknown) policy. In both stages, the incumbent and the challenger compete for contributions in order to cover the fixed cost of campaigning and to sway uninformed voters. The total level of contributions determines the probability of election for each candidate (i.e., all voters are uninformed). In the benchmark model, the candidates' policy positions do not result in any vote loss due to disappointed voters but we will relax this assumption in Sect. 4.1.

In the first stage, two opposing lobbies can buy candidates' policy support. A policy advocacy implies a major commitment to support and fight for mutually exclusive issues-a candidate cannot advocate free trade and import restrictions at the same time. ${ }^{9}$ The incumbent is approached first, giving him a first-mover advantage. He can opt for deflection or he can advocate. Deflection allows the candidate not to reveal his preferences, at the cost of forgoing contributions from a lobby. An advocacy position brings money to a candidate and it involves a disutility only if it is not in line with the candidate's preferred policy. Lobbies

\footnotetext{
${ }^{8}$ From 1975 to 2006, there were more than 1,000 AD cases but only 120 Section 301 investigations.

${ }^{9}$ The bright line between opposing positions which we draw here is of course a convenient simplification. We offer no model of 'advocacy specialization'. See Magee et al. (1989) for specialization models while Grossman and Helpman (1994, 1996) model non-specialized contributions.
} 
Table 1 Definitions

\begin{tabular}{ll}
\hline Notation & Definition \\
\hline$P$ & reduced form probability of the incumbent being elected \\
$p$ & objective probability of the incumbent being elected \\
$W$ & value of being elected \\
$\pi$ & cost of advocating unpreferred policy \\
$\Omega(\cdot), \Gamma(\cdot)$ & convex cost functions for providing access for incumbent and challenger \\
$\mu$ & recognition asymmetry (in favour of incumbent if $\mu>0.5 ; \mu \in[0,1])$ \\
$\beta$ & diminishing marginal effectiveness to effort $(\beta<1)$ \\
$e_{I}, e_{C}$ & effort spent by incumbent and challenger \\
$\bar{e}_{I}, \bar{e}_{C}$ & exogenous effort levels \\
$H_{I}, H_{C}$ & access provided by incumbent and challenger \\
$v\left(H_{I}\right), v\left(H_{C}\right)$ & downward sloping demand for access for incumbent and challenger \\
$C_{I}, C_{C}$ & advocacy contributions received by incumbent and challenger \\
$K_{I}, K_{C}$ & fixed cost of campaigning for incumbent and challenger \\
$b_{I}, b_{C}$ & marginal cost of effort for incumbent and challenger \\
$\gamma_{I}, \gamma_{C}$ & expected probability of support by uncommitted incumbent and challenger \\
$G$ & expected value of a committed politician for a lobby \\
$\alpha$ & share of informed voters \\
$\phi$ & vote gain $(\phi>0)$ or loss $(\phi<0)$ due to advocacy positions \\
\hline &
\end{tabular}

gain by having an elected politician supporting their cause (against the contribution that they have to pay).

In the second stage, a large number of heterogenous lobbies are interested in buying the option (which we call access) of some of the time of a potential elected politician. Politicians can and frequently do sell some of their time for listening to supporters of various issues and of different positions on such issues. Consequently, there is no strategic behavior among interest groups when buying access. Access contributions are costly to the recipient, if elected, since he has to spend some time listening to the various lobbies.

Given this setup, the expected utilities of incumbent $(I)$ and challenger $(C)$ are:

$$
\begin{aligned}
& E\left[\text { Utility }_{I}\right]=P\left[W-\pi-\Omega\left(H_{I}\right)\right], \\
& E\left[\text { Utility }_{C}\right]=(1-P)\left[W-\pi-\Gamma\left(H_{C}\right)\right],
\end{aligned}
$$

where $P$ is the reduced form probability of the incumbent being elected, $W$ is the value of being elected (there is no gain in case of electoral defeat), $\pi$ is zero when a candidate advocates his (privately known) preferred policy while it is positive when he advocates the other policy stance, and $\Omega(\cdot)$ and $\Gamma(\cdot)$ are convex cost functions for the access provided $\left(H_{I}\right.$ and $H_{C}$ ). $P$ depends on the contributions raised in the two stages of the campaign and it is derived in the following sections. Table 1 presents the notation and variable definitions used throughout the paper.

To explain the demand for protectionist pressure deflection such as $\mathrm{AD}$, we focus on the case where the Protectionist lobby approaches the incumbent, reflective of the more frequent case in which the status quo favors the Liberal lobby (nothing essential hangs on this asym- 
metry). ${ }^{10}$ The game tree in Fig. 1 illustrates the first stage of the game. The Protectionist lobby would like to have some trade protection imposed while the Liberal lobby supports free trade. The Protectionist lobby approaches the incumbent to ask for his support in imposing trade restrictions. The incumbent's response to the Protectionist lobby depends on his payoffs, which are in turn based on the subsequent moves of the lobbies and the second stage contest with the challenger. If the incumbent accepts to support the Protectionist advocacy, the best move of the Liberal lobby subsequently may be to fund the challenger. If the incumbent rejects the offer of the Protectionist lobby, the subsequent move of the Protectionist lobby may be to fund or not to fund a challenger. Rejecting to sponsor the advocacy position of the Protectionist group reveals that the incumbent is in favor of free trade. Thus, the Liberal lobby does not need to pay him money to back its cause since he is already on its side. If the incumbent deflects all pressures by invoking the AD channel, the best subsequent move of the Protectionist lobby may be to refrain from funding a challenger. In the latter case, and since the Liberal lobby will not fund a challenger when the incumbent deflects since the status quo favors its position, the incumbent benefits from deflection, referring the Protectionist lobby to a bureaucratic channel instead of taking a stance on protection. ${ }^{11}$ If a deflection channel were not available, an incumbent would be forced to take a stand on the lobby's advocacy request and reveal his preferences. His stand may imply contributions from a lobby, but the opposite lobby may fund and make a challenger viable. Therefore, deflection can deter the entry of a viable challenger by cutting off advocacy contributions that would be paid by special-interest groups. Such contributions, by lowering his net cost of campaigning, can make him viable and able to sell access because he has a chance of election. Although we assume that a challenger always enters (fitting the facts), he may be unable to raise enough money to campaign effectively (also fitting the facts). In this case we say no viable challenger enters the race and the race is effectively uncontested.

The regime of pressure deflection is selected in a metagame whenever the payoffs from deflection are positive for a sufficiently large (or influential) number of players. Here we abstract from the metagame stage for simplicity, but discuss it informally in Sect. 5. We concentrate on developing a formal model of the payoffs to incumbent politicians from the deflection regime.

The structure of the game where the access stage follows the advocacy decision is natural and analytically convenient. The lobby's request of support pushes the incumbent to reveal information about his positions if he does not deflect. This action changes the context of the electoral competition by modifying the lobbies' incentive to fund a challenger. At the same time, the value of access to the buyer depends on the probability of election of a candidate; this probability in turn being determined also by the advocacy positions. Thus, it is natural to place the advocacy decision prior to the access decision.

\footnotetext{
${ }^{10}$ Liberal is loosely applied here. Those opposing Protection do so in their narrow self-interested. A coalition of such interests is the Liberal lobby. A congressman who would accept a contribution from the Liberal lobby will have no use for protectionist pressure deflection for himself, so he does not contribute to the demand for protectionist pressure deflection. Such congressmen may well exist but our focus is on the demand for pressure deflection. Symmetrically, a congressman who would accept a contribution from the Protectionist lobby would not favor export pressure deflection.

${ }^{11}$ Figure 1 should show the possibility that the Liberal lobby approaches the incumbent when he deflects or rejects to support its advocacy positions and the Protectionist lobby pays a contribution to the challenger. These branches are not shown in the game tree since they are never chosen and would clutter the figure.
} 


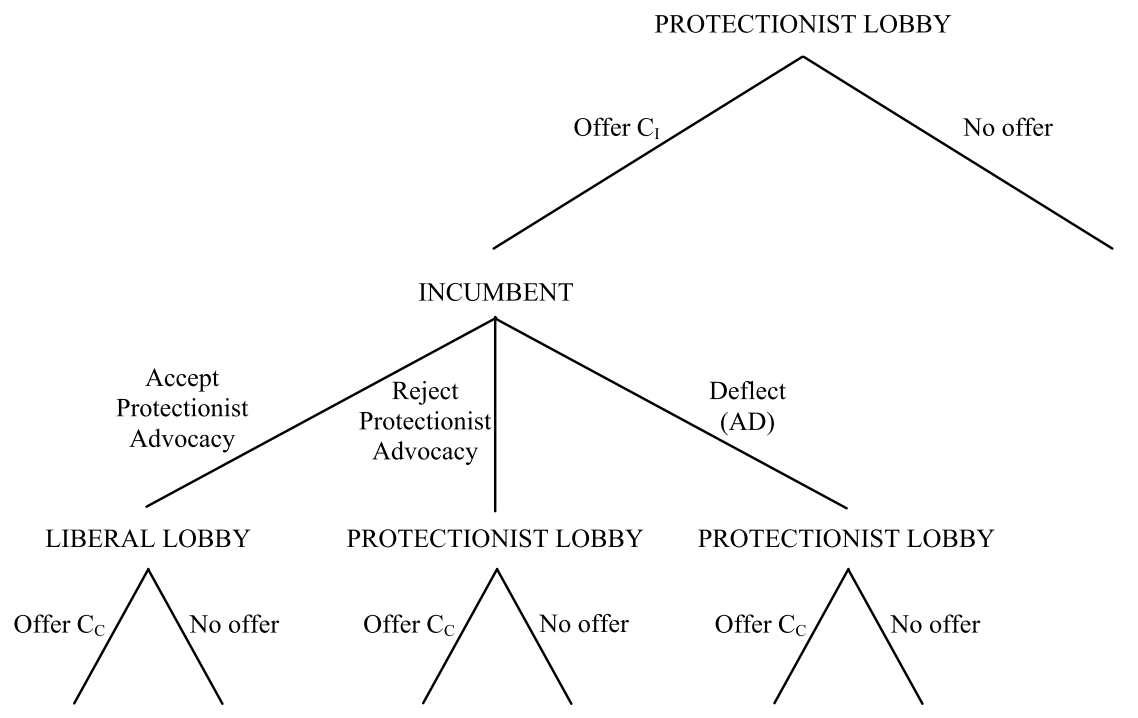

Fig. 1 Stage one game tree. Notes: $C_{I}$ and $C_{C}$ indicate an advocacy contribution for the incumbent and the challenger, respectively

\subsection{Second stage: access}

The model is solved by backward induction. In the second stage, the two candidates sell access taking as given the level of contributions raised through advocacy positions in the first stage. The objective probability that the incumbent wins the elections is ${ }^{12}$

$$
p=\frac{\mu e_{I}^{\beta}}{\mu e_{I}^{\beta}+(1-\mu) e_{C}^{\beta}}, \quad \beta<1, \mu \in[0,1],
$$

where $e_{I}$ and $e_{C}$ measure the effort invested by incumbent and challenger, respectively, in campaigning; $\mu$ represents an asymmetry between the two candidates (e.g., for $\mu>0.5$ the incumbent has an advantage) and the parameter $\beta<1$ imposes diminishing marginal effectiveness to effort. The specification in (3) assumes that the candidates' relative electoral effort is the only thing that matters in determining the outcome of the elections: uninformed voters are influenced only by the electoral campaign.

Each candidate faces a downward-sloping demand for access, $v\left(H_{I}\right)$ for the incumbent and $v\left(H_{C}\right)$ for the challenger. It is derived by aggregating the demand functions of the many heterogenous interest groups interested in purchasing some of the time of a potential elected politician. The actual price of access depends on the probabilities of election for each contestant since access has a value for the interest groups only if 'their' man is elected. Then, the price paid for access is $p v\left(H_{I}\right)$ for the incumbent and $(1-p) v\left(H_{C}\right)$ for the challenger.

We assume that effort is a linear function of the total funds raised, minus a fixed cost of the campaign ( $K_{I}$ for the incumbent and $K_{C}$ for the challenger):

$$
e_{I}=\bar{e}_{I}+\left[p v\left(H_{I}\right) H_{I}+C_{I}-K_{I}\right] / b_{I}
$$

\footnotetext{
${ }^{12}$ This probability should not be confused with the reduced form probability $P$ introduced earlier. The distinction between the two functions will be clear in a moment.
} 


$$
e_{C}=\bar{e}_{C}+\left[(1-p) v\left(H_{C}\right) H_{C}+C_{C}-K_{C}\right] / b_{C},
$$

where $\bar{e}_{I}$ and $\bar{e}_{C}$ are exogenous effort levels based on ideological attachments, name recognition or the like; $b_{I}$ and $b_{C}$ represent the marginal cost of effort; $p v\left(H_{I}\right) H_{I}$ and $(1-p) v\left(H_{C}\right) H_{C}$ are total revenues from access; and $C_{I}$ and $C_{C}$ denote contributions received from advocacy announcements in the first stage of the game. If a candidate is not able to raise enough resources to cover the fixed cost of campaign (i.e., the square brackets in (4) and (5) are negative), he will not be able to campaign actively and the opponent will win.

By substituting (4) and (5) into (3), the probability function can be written as

$$
p=\frac{1}{1+\frac{1-\mu}{\mu}\left(\frac{b_{I}}{b_{C}}\right)^{\beta}\left[\frac{b_{C} \bar{e}_{C}+(1-p) v\left(H_{C}\right) H_{C}+C_{C}-K_{C}}{b_{I} \bar{e}_{I}+p v\left(H_{I}\right) H_{I}+C_{I}-K_{I}}\right]^{\beta}}
$$

for nonnegative effort levels $e_{C}, e_{I}$. Equation (6) defines the probability of election only implicitly since $p$ appears on both sides. In the appendix we prove existence and uniqueness of the reduced form probability function $P\left(H_{I}, H_{C}, C_{I}, C_{C}, K_{I}, K_{C}\right)$.

The optimal level of access sold by the candidates is the solution to the simultaneous maximization of (1) and (2). The candidates sell finite amounts of access because of the corresponding cost they will incur when delivering the service if elected. The Nash equilibrium levels of $H_{I}$ and $H_{C}$ are found by solving the first-order conditions:

$$
\begin{aligned}
& P_{H_{I}}\left[W-\pi-\Omega\left(H_{I}\right)\right]-P \Omega^{\prime}\left(H_{I}\right)=0 \\
& -P_{H_{C}}\left[W-\pi-\Gamma\left(H_{C}\right)\right]-(1-P) \Gamma^{\prime}\left(H_{C}\right)=0,
\end{aligned}
$$

where $P_{H}$ denote partial derivatives. A candidate's probability of winning is increasing in the contributions he receives $\left(P_{H_{I}}>0\right)$ and decreasing in the other's $\left(P_{H_{C}}<0\right) .{ }^{13}$

In a symmetric Nash equilibrium $P=0.5$ and both candidates sell the same amount of access. Asymmetries between incumbent and challenger can lead to corner solutions where only one candidate receives funds and is elected with probability 1. Asymmetries between the two candidates are realistic since incumbents have an overwhelming advantage in congressional races. The key form of asymmetry, which is crucial to our story, is the difference in the level of contributions solicited in the advocacy stage where the incumbent can play strategically to make it impossible for a challenger to compete. Asymmetries can also arise exogenously because of name recognition, different cost functions (most probably the incumbent has a lower cost of providing the same services), different fixed costs of entering the electoral process or different demand functions for access. In this paper, we are concerned with the case where exogenous asymmetry is not so pronounced as to render deflection valueless.

Advocacy contributions have the effect of lowering the fixed cost that must be covered by access contributions. The results of Anderson and Prusa (2001a) in a model with only an

${ }^{13}$ The second-order conditions are

$$
\begin{aligned}
& P_{H_{I} H_{I}}\left[W-\pi-\Omega\left(H_{I}\right)\right]-2 P_{H_{I}} \Omega^{\prime}\left(H_{I}\right)-P \Omega^{\prime \prime}\left(H_{I}\right)<0, \\
& -P_{H_{C} H_{C}}\left[W-\pi-\Gamma\left(H_{C}\right)\right]+2 P_{H_{C}} \Gamma^{\prime}\left(H_{C}\right)-(1-P) \Gamma^{\prime \prime}\left(H_{C}\right)<0,
\end{aligned}
$$

where $\Omega^{\prime \prime}\left(H_{I}\right)$ and $\Gamma^{\prime \prime}\left(H_{C}\right)$ are positive because cost functions are convex; $P_{H_{I}} H_{I}$ and $P_{H_{C}} H_{C}$ are assumed to be small enough so that the second order conditions are satisfied. See Anderson and Prusa (2001a) for restrictions that ensure this result. The conditions hold for the simulations in Sect. 5. 
access stage can be used to determine the effect of advocacy contributions on access. Near the symmetric Nash equilibrium, an increase in advocacy contribution for one politician reduces the equilibrium level of access for both of them (strategic substitutes):

$$
\begin{aligned}
& \frac{d H_{j}}{d C_{j}}<0, \quad j=I, C \\
& \frac{d H_{k}}{d C_{j}}<0, \quad k, j=I, C ; \quad k \neq j .
\end{aligned}
$$

A higher advocacy contribution for a candidate will decrease his sale of access, which in turn will decrease the amount of access sold by the opponent. Following Anderson and Prusa (2001a), it is also possible to show that the decrease in the level of access is such that the direct effect of a contribution on the probability of election of the recipient is positive: $P_{C_{I}}>0$ and $P_{C_{C}}<0 .{ }^{14}$ Together, these results imply that a candidate's expected utility is increasing in the advocacy contribution he receives:

$$
\begin{aligned}
& \frac{d E\left[\text { Utility }_{I}\right]}{d C_{I}}=\left(P_{C_{I}}+P_{H_{C}} \frac{d H_{C}}{d C_{I}}\right)\left[W-\pi-\Omega\left(H_{I}\right)\right]>0, \\
& \frac{d E\left[\text { Utility }_{C}\right]}{d C_{C}}=-\left(P_{C_{C}}+P_{H_{I}} \frac{d H_{I}}{d C_{C}}\right)\left[W-\pi-\Gamma\left(H_{C}\right)\right]>0 .
\end{aligned}
$$

\subsection{First stage: the advocacy decision}

In the first stage the candidates must decide to advocate or not a policy position. ${ }^{15}$ The incumbent's advocacy decision precedes the challenger's advocacy decision and he can capitalize on his first-mover advantage by taking the contribution from the Protectionist lobby. Instead, the incumbent will not openly support free trade or reject the Protectionist lobby's offer since this will prompt the Protectionist lobby to approach the challenger without earning any advocacy contribution from the Liberal lobby since both actions reveal that the incumbent already favors free trade. ${ }^{16}$

The decision between advocating a position and deflection depends on the net benefit of each action. Analytically, given the solution of $H_{I}$ and $H_{C}$ from the second stage of the game (i.e., we impose subgame perfection), the incumbent chooses to advocate or deflect in order to maximize his expected utility. Given the incumbent's action, the challenger will advocate a cause, provided that a lobby would be interested in securing his support. ${ }^{17}$ The

\footnotetext{
${ }^{14}$ The total effect of contributions on $P$ is given by $\frac{d P}{d C_{I}}=P_{C_{I}}+P_{H_{I}} \frac{d H_{I}}{d C_{I}}+P_{H_{C}} \frac{d H_{C}}{d C_{I}}$ and $\frac{d P}{d C_{C}}=$ $P_{C_{C}}+P_{H_{I}} \frac{d H_{I}}{d C_{C}}+P_{H_{C}} \frac{d H_{C}}{d C_{C}}$. It is reasonable to assume $\frac{d P}{d C_{I}}>0$ and $\frac{d P}{d C_{C}}<0$ since a rise in the advocacy contribution should not decrease the equilibrium probability of a candidate. These signs hold if $P_{H_{I}} \frac{d H_{I}}{d C_{I}}$ and $P_{H_{C}} \frac{d H_{C}}{d C_{C}}$ are small enough compared to the other terms in each expression. In our simulations, these signs always obtain.

${ }^{15}$ We take as given the decision to enter the electoral campaign since in the model the outside option is zero. For the incumbent, the entry decision is already made (for simplicity). As for the challenger, the evidence suggests that a challenger will always enter the race, but he often will not be viable in the sense of attracting contributions.

${ }^{16}$ We will allow for advocacy positions to affect voting decisions in Sect. 4.1.

${ }^{17}$ We assume that a lobby cannot foreclose entry of a 'second' challenger by offering the same advocacy position to incumbent and challenger. Then, supporting incumbent and challenger is a dominated strategy. In
} 
Table 2 Lobbies' payoffs

Liberal

\begin{tabular}{lll}
\hline$C_{I}=0, C_{C}=0$ & $\left(1-\gamma_{I}\right) \hat{P} G+\left(1-\gamma_{C}\right)(1-\hat{P}) G$ & $\gamma_{I} \hat{P} G+\gamma_{C}(1-\hat{P}) G$ \\
$C_{I}=0, C_{C(\text { pro })}>0$ & $\left(1-\gamma_{I}\right) \bar{P} G$ & $\gamma_{I} \bar{P} G+(1-\bar{P}) G-C_{C}$ \\
$C_{I(\text { pro })}>0, C_{C}=0$ & $\left(1-\gamma_{C}\right)(1-\underline{P}) G$ & $\underline{P} G+\gamma_{C}(1-\underline{P}) G-C_{C}$ \\
$C_{I(\text { pro })}>0, C_{C(l i b)}>0$ & $(1-\widetilde{P}) G-C_{C}$ & $\widetilde{P} G-C_{I}$ \\
\hline
\end{tabular}

challenger will always sponsor an advocacy position (if offered such opportunity), but he does not consider the option of the AD law because it would entail zero contributions.

The analytical solution of this stage coincides with the equilibrium of the two-stage game given by $\left\{H_{I}^{*}, H_{C}^{*}, C_{I}^{*}, C_{C}^{*}\right\}$, which in turn determines the probability of election for the incumbent $(P)$ and the challenger $(1-P)$. The complexity of the model does not allow us to fully characterize the solution in an analytical way. We discuss some theoretical implications in Sect. 4 but we will have to simulate the model numerically over different parameter ranges in order to illustrate the solution of the model.

\subsubsection{Lobbies' behavior}

At the advocacy stage there are only two lobbies on opposite sides of a single issue (free trade). As for their payoffs, we assume that a lobby gains $G$ in expected value when a committed politician is elected and a contribution is paid to the incumbent $\left(C_{I}\right)$ or the challenger $\left(C_{C}\right)$. If no advocacy contribution is paid, the preferences of the candidates are not revealed and the lobbies expect a re-elected incumbent to support the protectionists' demand with a probability $\gamma_{I}$. Similarly, an uncommitted challenger is expected to support the protectionists' demand with a probability $\gamma_{C}$. Using these expectations, we define the probability of incumbent re-election as $\hat{P}$ when there are no advocacy contributions on either side and $\tilde{P}$ when both sides obtain advocacy contributions, while $\bar{P}$ and $\underline{P}$ denote the probabilities when just one candidate advocates.

Given this setup, Table 2 reports the expected utility for each lobby in each possible case where the subscripts (pro) and (lib) indicate which lobby contributes to a candidate. If the incumbent accepts an advocacy position, it would be from the Protectionist lobby since we assume that free trade is the status quo and the AD channel can only deflect the pressure for trade protection. And if the incumbent deflects, the offer to the challenger to support a particular policy position can only be made by the Protectionist lobby (see Fig. 1).

The two lobbies have to decide how much to contribute to incumbent and challenger. This poses a difficult modeling problem because of the strategic interactions between two lobbies on one side and two politicians on the other side, with the incumbent having a firstmover advantage. We resolve the problem by assuming that there is an infinitely elastic supply of challengers with zero reservation utility, so 'the' challenger is unable to extract rents from the lobby. Then, the lobby approaching the challenger will offer him its optimal contribution subject to doing better than with a zero contribution. When $G$ is not too large, this is the minimal contribution needed to make the challenger viable. For sufficiently large $G$, it is possible that the optimal contribution is larger. ${ }^{18}$

practice, lobbies typically do not support multiple candidates with the same advocacy position while they do pay access contributions to more than one candidate.

${ }^{18}$ In a neighborhood of the symmetric equilibrium, advocacy contributions reduce the level of access sold by the candidates (see Sect. 3.1) and this always holds in our simulations. Still, if $G$ is large enough, the lobby 
The contribution paid to the incumbent is the outcome of a game between him and the Protectionist lobby. For our purposes it is unnecessary to model this complex game, hence we do not pin down the exact amount of the contribution and escape imposing any ad hoc specification on the interaction between lobby and incumbent. We need only consider if there is a contribution level such that both lobby and incumbent gain. If this is the case, we assume that the incumbent does not deflect. In contrast, we assume that the incumbent deflects if the maximum amount that the Protectionist lobby is willing to offer does not make the incumbent better off with respect to the rejection of the advocacy position.

\section{Theoretical implications}

Consider first the limiting case where the cost of entry is zero for both candidates. Then, a lobby would always find it optimal to contribute to the challenger independently of the incumbent's advocacy position. From a lobby's perspective, paying a small contribution guarantees the candidate's support if elected. For the challenger, any contribution increases his probability of election because of the extra funds he has to spend on advertisement and the possibility to re-optimizing the amount of access. Thus, the incumbent will accept to support the Protectionist advocacy himself since deflecting the pressure does not prevent the challenger from being offered an advocacy contribution. Formally:

Proposition 1 Deflection is not the optimal strategy for the incumbent if the challenger is viable without advocacy contributions.

Proof see the Appendix.

In other words, a necessary condition for deflection is that the challenger is not viable without advocacy contributions. ${ }^{19}$ Against this backdrop, consider a case where $K_{C}$ is high enough so that the challenger is not viable if he does not receive advocacy contributions (i.e., his expected utility without advocacy contributions is not strictly positive). What should the incumbent do taking into consideration the lobbies' best response (i.e., the lobbies' optimal level of contribution)? The answer depends on the values of $G$ (i.e., the lobby's expected utility of a committed politician). If the challenger is not offered an advocacy contribution, he will not be viable and the incumbent will be re-elected. Taking two extreme cases clarifies the situation: when $G=0$ the Protectionist lobby does not have any incentive to contribute to the challenger when the incumbent deflects but when $G$ is very large it gains by making the challenger a viable candidate. By continuity, there exists a critical value of $G$ that makes it worth it for a lobby to offer a challenger the possibility to sponsor an advocacy position. Thus:

\section{Proposition 2 Deflection is the optimal strategy for the incumbent if}

i) the challenger is not viable without advocacy contributions and

ii) $G$ is below the critical level $G^{*} \equiv C_{C} /\left[\left(1-\gamma_{C}\right)(1-\hat{P})-\left(1-\gamma_{I}\right)(\hat{P}-\bar{P})\right.$.

Proof see the Appendix.

finds it optimal to pay more than the minimal contribution: the gain from the higher probability times the large $G$ compensates for the lower level of access sold by the challenger.

${ }^{19}$ Anderson and Prusa (2001a) show that small fixed costs can make the challenger not viable. 


\subsection{Cost of advocacy}

An implicit assumption of the model is that a candidate does not lose votes when advocating a cause (e.g., from voters who disapprove of his policy stance). The results presented are sensitive to this assumption and it is therefore worthwhile exploring the possibilities for relaxing it.

One possibility is to allow for the existence of informed and uninformed voters. Informed voters would vote depending on the advocacy positions supported by the candidates. The probability function could then be generalized following Baron (1994):

$$
p=\alpha\left(\frac{1}{2}+\phi\right)+(1-\alpha) \frac{\mu e_{i}^{\beta}}{\mu e_{i}^{\beta}+(1-\mu) e_{c}^{\beta}} ; \quad|\phi|<\frac{1}{2},
$$

where $\alpha(0<\alpha<1)$ represents the fraction of informed voters while uninformed voters behave as before. $\phi$ represents the portion of informed voters the incumbent loses $(\phi<0)$ or gains $(\phi>0)$ because of the advocacy positions chosen by both candidates. ${ }^{20}$

Such an extension would make deflection more or less likely depending on the directions in which informed voters respond to the advocacy positions. If an advocacy position attracts more informed voters than those that switch to the other candidate (i.e., $\phi>0$ ), the incentive to deflect should become less important because of the effect of increased voter support on the probability of election. Even when a policy advocacy earns some votes, deflection will still be optimal for the incumbent in situations where the gain in the expected utility from deflection is large enough. But if the net result of an advocacy position is to lose informed voters (i.e., $\phi<0$ ), the incentive for deflection should become stronger. Hence, the results are qualitatively the same as those presented earlier.

\section{Choosing the deflection regime}

Previous sections give conditions under which incumbent legislators would make use of the option of deflecting policy pressure. Those politicians who foresee using the option would surely favor a pressure deflection regime because it raises their chances of an easy election. The substantial number of essentially unopposed congressional races suggests the potential popularity of deflection. Those who foresee advantages in accepting advocacy positions, in contrast, should oppose deflection. The diverging views can be lined up on a single issue such as a vote on fast track authority, with the median legislator's views prevailing. Epstein and O'Halloran (1999) provide a thorough formal analysis of this rules-setting stage of the metagame in their transaction-cost model of delegation. Pressure deflection simply provides a new motive in their setting for legislators to vote for or against delegation.

An important general equilibrium force amplifies the desirability of a deflection regime for incumbent legislators. When trade is 'politicized', as in the U.S. political regime prior to 1934 , many politicians can be swayed to support protection while many others can be swayed to oppose it. Then, the gains $G$ to the lobbies from winning over one more, possibly swing, supporter to their side are increased as compared to the case where trade is less political. An incumbent who foresees the general equilibrium effect recognizes that both lobbies' gains from supporting a challenger are increased by politicization, so even if he does

\footnotetext{
${ }^{20}$ It is simple to prove existence and uniqueness of the reduced form probability for this generalized function following the proof in the Appendix.
} 
plan to advocate protection, his potential challenger is less likely to be supported under a deflection regime. The incumbent can sympathetically refer the lobby's case to the executive while continuing to hide his true preferences, and the availability of this option to all his colleagues lowers the value of advocacy positions to all. This is our stylized version of the political institutions of U.S. trade policy.

This general equilibrium force may help to explain the durability of the regime shift: once in place, pressure deflection was understood to be very helpful to incumbents as pressure groups concentrated efforts on the president. The general equilibrium effect may also explain the emergence of refinements such $\mathrm{AD}$ and unilateralist export promotion through Section 301 of the Trade Act of 1974. Political pressures on Congress to intervene in trade rose in the 1970s with the switch of trade unions to protectionism. This occurred as the era of detente with Communist countries reduced the appeal of the Cold War rationale for liberal trade as part of patriotic foreign policy. The innovations of the Trade Act of 1974 can be understood as a response which lowered the gains $G$ which lobbies might obtain by securing the support of a member of Congress. The Act was the creation of liberal traders, such as Wilbur Mills, under the name of averting still more protectionist outcomes.

Our story explains the trend we can detect when observing the evolution of $\mathrm{AD}$ as a protectionist tool. From its introduction in 1916 until the beginning of the 1980s, the U.S. AD law was little used because of its technicalities. However, the Trade Agreements Act of 1979 changed this situation by making it easier for an industry to obtain AD protection. The discovery of its political value by import-competing special interests and by the Congress led to an explosion of AD cases. It also led to further 'refinements' to the AD law. Among others, the cumulation requirement, which requires the cumulation of imports from different countries when determining injury, implemented in 1984 and the provisions of the Uruguay Round reinforced once more the use of AD petitions. The final stage in this evolutionary process was a bill approved by the U.S. Congress in 2000 which provides for the revenue from $\mathrm{AD}$ duties to be redistributed to the firms that file the $\mathrm{AD}$ petition. ${ }^{21}$

We speculate that the pressure deflecting advantages of delegated authority may have some appeal in parliamentary democracies. However, the present model would need to be modified to incorporate the strategic interactions between individual members and their party, which can take advocacy positions and distribute contributions. The party would calculate the value of backing an advocacy position versus deflection depending on the number of races which could become uncontested in case of no advocacy position being accepted. This seems another interesting application of the logic of political pressure deflection which we leave for future work. ${ }^{22}$ This venue is the more interesting given the large number of developing countries that recently adopted and started using AD (see Zanardi 2004). The considerable heterogeneity of this set of countries suggests that pressure deflection cannot be the only (or main) explanation of AD law adoption, which would make an in-depth analysis of various country cases all the more relevant. ${ }^{23}$

\footnotetext{
${ }^{21}$ In 2003 the WTO Dispute Settlement Panel ruled against this amendment to the U.S. AD law. The United States changed its legal provisions with effect from October 2007.

${ }^{22}$ Adapting the model to the case of the European Union (i.e., the other major user of AD among developed countries) would require further modifications. In fact, $\mathrm{AD}$ investigations are delegated to the European Commission but member states vote by majority on the imposition of final duties. The public interest provision of the EU AD law (i.e., $\mathrm{AD}$ measures should be in the interest of the EU community at large) may also play a role, although it has been rarely used to dismiss $\mathrm{AD}$ cases.

${ }^{23}$ Pressure deflection may not play any role in countries whose governments are theoretical immune to political contributions (e.g., China).
} 


\section{Simulations}

The two-stage game does not allow a closed form solution. Thus, we rely on simulations to illustrate the conditions such that the incumbent favors the use of the AD law over the support of the Protectionist lobby via advocacy contributions. These conditions hinge on asymmetries between incumbent and challenger, which can arise from many dimensions.

The simulations are constructed as follows. ${ }^{24}$ For a given range of possible advocacy contributions to the incumbent, the equilibrium of the model (i.e., access sold by candidates, probability of election, expected utility of candidates) is calculated for all possible levels of a given range of advocacy contributions to the challenger. ${ }^{25}$ For each of these equilibria, the expected utilities of the two lobbies are computed as a function of $G$. Then, for each value of $G$ and taking as given the advocacy contribution paid to the incumbent, we determine the optimal choice of the lobby contributing to the challenger.

From these simulations, we observe different results depending on the value of $G$. When $G$ is below a critical value, the expected utility of the lobby contributing to the challenger is maximized when no advocacy contribution is paid to any candidate. The other lobby could increase its utility if the incumbent advocates its cause but any payment from this lobby would not be enough to make 'no deflection' the optimal choice for the incumbent. Therefore, the incumbent deflects. When $G$ is above the critical value, a lobby is willing to make the challenger viable independently of the advocacy contribution paid to the incumbent. Also, there is a range of contributions to be paid to the incumbent such that both the Protectionist lobby and the incumbent gain over the outcome where no contribution is paid to the incumbent. In this case, the incumbent does not deflect.

In the following, we present simulations where we normalize $K_{I}=0$ and investigate the results of the model for values of $K_{C}$ from 0 to 0.99 , the upper bound being chosen to satisfy the condition for uniqueness of the equilibrium (see the Appendix). The intuition behind the two propositions presented earlier has its counterpart in the simulations reported in Fig. 2. For each given value of $K_{C}$, the incumbent finds it optimal to deflect pressure when the value of $G$ for the Protectionist lobby is below the line. Note that for $K_{C}<0.35$ the incumbent will never deflect. This is the critical value that makes a challenger viable or not and it provides a 'numerical proof' of Proposition 1 that states that deflection is never the optimal strategy for the incumbent when the challenger is viable even if he does not receive advocacy contributions. The intuition is simple. When the challenger is viable, a lobby would always find it optimal to ask him to support its policy positions. As a consequence, the incumbent's best response is to cash in as much as possible and he does not deflect.

The importance of Fig. 2 is to show that had the AD channel not been available, a challenger would have managed to enter the race when $K_{C}>0.35$ thanks to the advocacy position. In fact, had the incumbent not deflected the challenger would have been offered enough

\footnotetext{
${ }^{24} \mathrm{We}$ assume the following functional forms and parameter values: $W=10 ; \pi=0 ; \beta=0.5 ; \mu=0.5 ; b_{I}=$ $b_{C}=1 ; \gamma_{I}=\gamma_{C}=0.5 ; \bar{e}_{I}=\bar{e}_{C}=1 ; v\left(H_{I}\right)=H_{I}^{-0.7} ; v\left(H_{C}\right)=H_{C}^{-0.7} ; \Omega\left(H_{I}\right)=H_{I}^{2} ; \Gamma\left(H_{C}\right)=H_{C}^{2}$. Since there is no a priori belief about the challenger's true positions, we set $\gamma_{C}=0.5$; analogously, we also set $\gamma_{I}=0.5$. With respect to the candidates' policy preferences, there are four possible random draws of incumbent and challenger (i.e., both protectionist, both liberal, one liberal and the other protectionist and vice versa). In each case, a candidate may accept advocacy contributions aligned or not with his policy preferences for a total of eight cases (since we exclude that both candidates advocate the same position) and our current simulations cover one of these cases where the advocacy positions, if accepted, are in line with the candidates policy preferences (i.e., $\pi=0$ ). However, any of the other seven cases maps into simulations with different $W \mathrm{~s}$ which would give different numerical results but the same qualitative conclusions.

${ }^{25}$ We checked that the second order conditions in footnote 13 hold.
} 


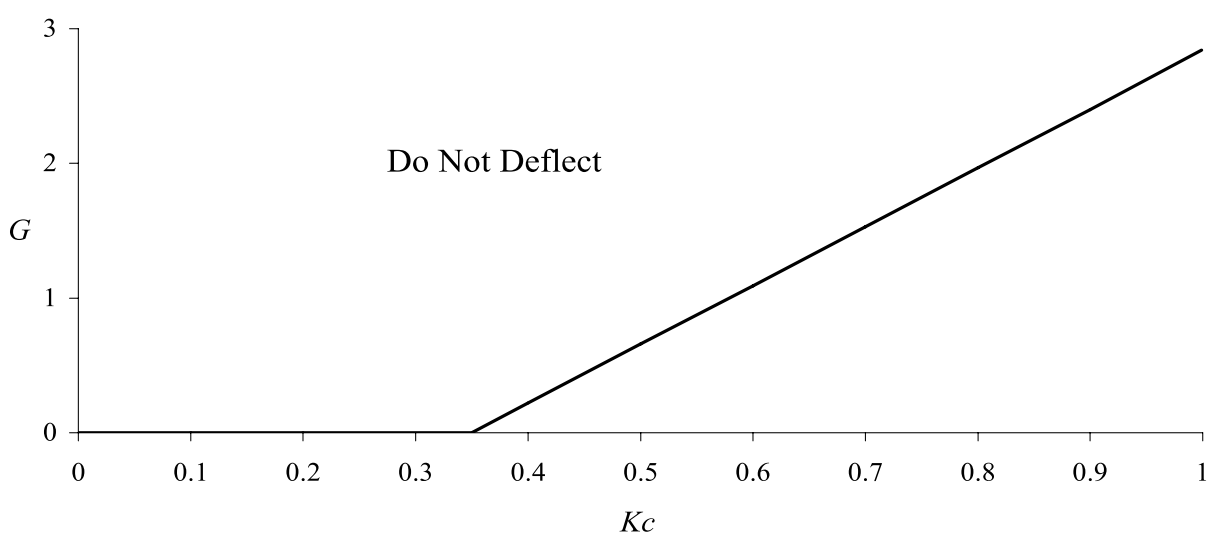

Fig. 2 Incumbent's decision to deflect. Notes: $K_{I}=0$; other values as from footnote 24

money for his policy support to make him viable. Instead, for values of $G$ below the line, the existence of a pressure deflecting mechanism allows the incumbent to conceal his policy position therefore eliminating the incentives for a lobby to fund the challenger.

It is worth nothing the great deal of linearity in Fig. 2 and in the simulations that follow. This may seem strange at first given that the model is highly nonlinear. However, in each figure an increase in the level of $K_{C}$ needs to be matched by a proportional increase in $C_{C}$ in order for the challenger to be viable. The lobby will always contribute the minimum amount to allow the challenger to compete and this increases proportionally with $K_{C}{ }^{26}$ Proportionally higher levels of $G$ are then necessary to make it optimal for the lobby to fund the challenger and this explains the upward sloping curves. The linearity comes from the constant proportional increase in $C_{C}$ needed to balance the increased cost of entry. Since in the simulations we assume $\gamma_{I}=\gamma_{C}=0.5$, Proposition 2 shows that this proportionality amounts to $2 /(1-\bar{P})$.

\subsection{Asymmetries in lobbies' gains}

Lobbies may assign a higher value if a re-elected incumbent supports their cause instead of an elected challenger. This sounds reasonable since an incumbent knows how the political system works and because of his already established connections and reputation.

This situation is going to enlarge the range of values for which the incumbent deflects the pressure on the AD authority. A lobby may be better off by not making the challenger viable when the incumbent deflects if in any case the expected value of an elected challenger is much lower than an uncertain support from a much higher valued incumbent. Then, for each given asymmetry between incumbent and challenger, there is a gap between challenger and incumbent's support that makes deflection the incumbent's best option where a common value of $G$ delivered by the two candidates would not have made it. This result can be seen in Fig. 3 where the $45^{\circ}$ line replicates earlier results where the value of $G$ is common for both candidates. For $K_{C}=0.5$ the area above the $45^{\circ}$ line and the dotted line represents combinations of expected gain from incumbent $\left(G_{I}\right)$ and challenger $\left(G_{C}\right)$ where deflection

\footnotetext{
${ }^{26}$ This depends on the assumption of an infinite supply of potential challengers, which makes it impossible for 'the' challenger to extract rents from the contributing lobby.
} 


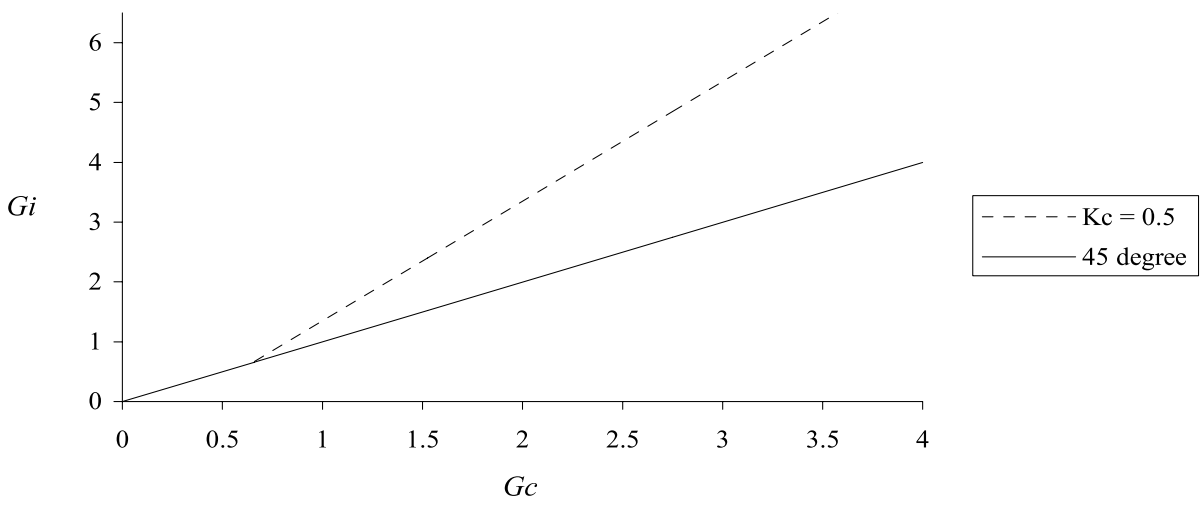

Fig. 3 Asymmetry in $G$. Notes: $K_{I}=0$; other values as from footnote 24

is the optimal strategy. The point where the dotted line departs from the $45^{\circ}$ line is the value found in Fig. 2 for the same level of $K_{C}$. Below that level, the incumbent deflects even when the $G$ s are the same for the candidates. However, above that point deflection does not occur except if $G_{I}$ is greater than $G_{C}$. In particular, the difference between these two values must be such that $G_{I}$ is on or above the dotted line for each corresponding value of $G_{C}$.

More simulations could be presented detailing the effect of other comparative static exercises. The qualitative results would not change: for each parameterization there exists a critical value of $G$ that distinguishes if it is optimal or not for the incumbent to deflect. In particular, any asymmetry in favor of the incumbent (e.g., $\mu>0.5$ ) requires an increasingly higher value of $G$ for the incumbent not to deflect.

\section{Conclusions}

The main contribution of this paper is to provide a political economy rationale for pressure deflecting institutions. An important example is the U.S. trade policy machinery, characterized by delegation of trade policy to the executive and reinforced by safety-valve deflection typified by AD. Although in this paper pressure deflection is identified with the AD system, the argument itself is much more general and may be applied to other regulatory agencies, albeit trade policy is the most striking example.

Our story addresses an important anomaly in modern political economy. Delegation of trade policy, especially understood as pressure deflection, is directly contrary to the political economy approach that explains trade protection as the result of a quid pro quo between politicians and lobbies. With 'policy for sale', an incumbent politician would like more policy to sell in order to secure greater electoral success. In contrast, in our model an incumbent politician, by deflecting political pressure, can conceal his true position and decrease the incentive for lobbies to fund a challenger to advocate their causes. In such cases, potential challengers may be at a disadvantage in attracting contributions and may not become viable. Their effective entry is blockaded.

The solution we propose for the puzzle posed by pressure deflection is also consistent with the empirical observation that many electoral races are uncontested (i.e., only one candidate running in the elections). A popular explanation is the so-called 'war chest' argument by which a candidate (usually the incumbent) accumulates a lot of money in the early stage 
of the electoral competition and this makes it impossible for a challenger to raise enough funds. Instead, in our model a strategic decision of the incumbent to raise financial barriers eliminates the incentive for lobbies to give contributions to a potential challenger. These financial barriers go exactly in the opposite direction of the typical war-chest argument since the incumbent is actually accumulating fewer contributions because lobbies do not pay him anything when he deflects. ${ }^{27}$

AD law is rationalized as a complement to the overall delegation regime of U.S. trade policy. It provides a way for liberal-trade incumbents to hide their policy preferences and still not disappoint a Protectionist lobby. It is tempting to speculate that the rise in the use of $\mathrm{AD}$ in the early 1980s coincided with the decline of liberal internationalist ideological support for liberal trade in the Congress and among opinion elites. Pure delegation does not serve to insulate incumbents from political pressure when the delegation regime itself is in doubt, as we have argued above. In this case the safety valve provided by AD law may have served to fortify the delegation regime. We concede against this speculation that the longstanding AD law was virtually unused until the early 1980s while its expansion then may be simply due to the belated and fortuitous discovery of its usefulness by protectionists. In favor of the speculation, the expansion and protection of AD law by Congress since then have strengthen pressure deflection and incumbency advantage in an era when trade policy is hotly debated.

Another implication of our story is that the AD law creates political as well as economic inefficiency by raising barriers to the viability of challengers, reinforcing the advantage that incumbents usually have. If the incumbent is uncontested, he will not sell any access. Thus by increasing the likelihood of one-horse races, the AD law creates political inefficiency in the form of a lack of communication with the elected politician on top of the well-documented economic inefficiencies stemming from its implementation (see Blonigen and Prusa (2003) for a survey of the effects of an AD law). More speculatively, pure delegation as pressure deflection may be politically inefficient. By deflecting interest groups away from urging policy advocacies, allowing politicians to conceal positions and limiting political competition of viable candidates, it is possible that valuable information is suppressed and worse choices are made by democratic processes. Notions of campaign finance 'reform' suggest that getting money out of politics is desirable, but in our model the reduced sale of access is presumptively undesirable because advocates of various interests are unable to obtain access to present their information.

The theoretical conclusions we derived lead to interesting testable implications for future research. Based on the model, we should observe that very strong incumbents advocate less because of their favorable asymmetry with respect to their challengers. However, this is not inherently true for every incumbent since the relative asymmetry with the challenger is the relevant key factor. In this sense, a strong incumbent in absolute terms may still be in a position to advocate if running against a favorable challenger. The variability observed over many cycles of elections for the U.S. Congress should make it possible to identify the decision to advocate as a function of the asymmetry among candidates. For example, years of elected service and membership in House or Senate committees would be obvious proxies for the asymmetries in favor of the incumbent. In contrast, when considering open-seat

\footnotetext{
${ }^{27}$ This explanation is consistent with the empirical results in Anderson and Prusa (2001b) who conclude that early contributions to one candidate do not cause lower later contributions to the other candidate. Hence, they speculate that differences in the level of contributions are the outcome of inherent asymmetries between incumbent and challenger. Our model explains how an asymmetry can work in the direction to favor the incumbent without necessarily implying a strategic accumulation.
} 
races we should expect to observe relatively more advocacy positions taken since candidates are usually more similar than when an incumbent is running for re-election. The large set of countries now using AD may also allow a cross-country comparison although the empirical exercise would not look at the actual use of AD but at the decisions of candidates (incumbents versus challengers) to advocate or not major policy issues. The heterogeneity in the legal details of $\mathrm{AD}$ laws across countries would help in disentangling the value of pressure deflection since different systems allow for different degrees of political involvement in AD. Against this backdrop, the challenge of such an empirical analysis is that a candidate's decision on a particular policy advocacy would also be influenced by his overall policy platform, which may not be easy to capture empirically.

Although our main contribution is to explain pressure deflection with an interesting application to U.S. trade policy and AD law, this paper also offers a particular characterization of electoral ambiguity. In fact, the key feature of deflection is the ability for the incumbent to remain ambiguous on his policy preferences. Contrary to the literature where ambiguity pays off in terms of votes, ambiguity endogenously arises in this model in order to deter challengers to become viable candidates. In this sense, it is important to point out that the advantage of ambiguity is not only confined to trade policy. Pressure deflection may be relevant whenever the preferences of politicians are not known but there are lobbies on the opposite side of a policy issue while voters do not have strong opinions about it.

Acknowledgements The authors would like to thank Hideo Konishi, Vasso Ioannidou, the editor William Shughart II, two anonymous referees and seminar participants at the Catholic University of Leuven, Dartmouth College, the University of Edinburgh, the University of Stirling, the EEA Conference in Venice, the North American Winter Meeting of the Econometric Society in Washington DC, and the ETSG Conference in Nottingham for useful suggestions. Any remaining errors are solely ours.

Open Access This article is distributed under the terms of the Creative Commons Attribution Noncommercial License which permits any noncommercial use, distribution, and reproduction in any medium, provided the original author(s) and source are credited.

\section{Appendix}

Existence and uniqueness

Using the same notation as in Anderson and Prusa (2001a), Equation (6) yields

$$
p=\frac{1}{1+\omega\left[\frac{b_{C} \bar{e}_{C}+(1-p) v\left(H_{C}\right) H_{C}+C_{C}-K_{C}}{b_{I} \bar{e}_{I}+p v\left(H_{I}\right) H_{I}+C_{I}-K_{I}}\right]^{\beta}}=g\left(p, H_{I}, H_{C}, C_{I}, C_{C}, K_{I}, K_{C}\right),
$$

where $\omega=\frac{1-\mu}{\mu}\left(\frac{b_{I}}{b_{C}}\right)^{\beta}$. The reduced form probability function is

$$
P\left(H_{I}, H_{C}, C_{I}, C_{C}, K_{I}, K_{C}\right)=\left\{p: p=g\left(p, H_{I}, H_{C}, C_{I}, C_{C}, K_{I}, K_{C}\right)\right\} .
$$

The setting in Anderson and Prusa (2001a) is different from the one applied in this paper since they assume that if a candidate does not raise enough revenue to cover the fixed cost of entry, he will still have the exogenous level of effort $\bar{e}$. Instead, we assume that in this case he does not enter the race and the opponent wins with probability 1 . In their model, existence of the fixed point solution of the equation in (A1) follows from the fact that $g(p, \cdot)$ is continuous on the unit interval and as long as at least one candidate campaigns actively $1>g(1, \cdot)>g(\bar{p}, \cdot)>g(\underline{p}, \cdot)>g(0, \cdot)>0$, where $\bar{p}$ and $\underline{p}$ are the probability where the 
challenger and the incumbent do not actively campaign, respectively. Hence, $g(p, \cdot)$ must cross the $45^{\circ}$ line satisfying $p=g(p, \cdot)$ in the unit interval, hence a fixed point exists.

For $\bar{p}$ such that $(1-p) v\left(H_{C}\right) H_{C}+C_{C}-K_{C}=0, g(p, \cdot)$ is not continuous in our case. ${ }^{28}$ However, except for the zero probability case where the fixed point occurs at $\bar{p}$, our model has a fixed point as well. It is given by the same point as in Anderson and Prusa (2001a) if it occurs for $p<\bar{p}$ and equal to 1 if it occurs in the range for $p>\bar{p}$.

Having proved existence, there is no guarantee that the solution is unique. Again, Anderson and Prusa (2001a) determine over-sufficient (not necessary) conditions by imposing that $g_{p}<1$ for $p \in[0,1]$. Differentiating $g(p, \cdot)$ in the interval $p<p<\bar{p}$

$$
g_{p}(p, \cdot)=\beta g(1-g)\left(A_{C}+A_{I}\right) \geq 0,
$$

where $A_{C} \equiv \frac{v\left(H_{C}\right) H_{C}}{b_{C} \bar{e}_{C}+(1-p) v\left(H_{C}\right) H_{C}+C_{C}-K_{C}} \geq 0$ and $A_{I} \equiv \frac{v\left(H_{I}\right) H_{I}}{b_{I} \bar{e}_{I}+p v\left(H_{I}\right) H_{I}+C_{I}-K_{I}} \geq 0$.

Examining the expression for $g_{p}$, uniqueness cannot generally be guaranteed, since $A_{c}+A_{i}$ can exceed one by enough to offset the influence of the first three terms. For large $v\left(H_{c}\right) H_{c}$ and $v\left(H_{i}\right) H_{i}$, at equilibrium $p, A_{c}+A_{i}$ converges to $1 / p(1-p)$ while at equilibrium $g=p$; thus $g_{p}$ converges to $\beta$. As $v\left(H_{c}\right) H_{c}$ and $v\left(H_{i}\right) H_{i}$ change for given $p$, their effect on $g_{p}$ is signed by

$$
\begin{aligned}
& \frac{\partial A_{c}}{\partial H_{c}}=A_{c} \frac{b_{c} \bar{e}_{c}-K_{c}}{H_{c}\left[b_{c} \bar{e}_{c}+(1-p) v\left(H_{c}\right) H_{c}-K_{c}\right]}\left(1-1 / \varepsilon_{c}\right), \\
& \frac{\partial A_{i}}{\partial H_{i}}=A_{i} \frac{b_{i} \bar{e}_{i}-K_{i}}{H_{i}\left[b_{i} \bar{e}_{i}+p v\left(H_{i}\right) H_{i}-K_{i}\right]}\left(1-1 / \varepsilon_{i}\right),
\end{aligned}
$$

where the elasticities are $\varepsilon_{i} \equiv-v\left(H_{i}\right) /\left[v^{\prime}\left(H_{i}\right) H_{i}\right]>1$ and $\varepsilon_{c} \equiv-v\left(H_{c}\right) /\left[v^{\prime}\left(H_{c}\right) H_{c}\right]>1$.

The elasticities are above 1 as the condition for positive marginal revenue from contributions, a necessary condition for positive marginal benefit of contributions for the candidates. Examining the derivatives of $A, A_{c}+A_{i}$ rises with contributions for given $p$ as $b_{i} \bar{e}_{i}-K_{i}>0$ and $b_{c} \bar{e}_{c}-K_{c}>0$, while $A_{c}+A_{i}$ falls with contributions as $b_{i} \bar{e}_{i}-K_{i}<0$ and $b_{c} \bar{e}_{c}-K_{c}<0$. When $A_{c}+A_{i}$ is increasing in contributions for given $p$, its maximum value is equal to $1 / p(1-p)$, hence $g_{p} \leq \beta$ for any equilibrium value of $p$. Therefore a sufficient condition for uniqueness is $\beta<1, b_{i} \bar{e}_{i}-K_{i}>0$ and $b_{c} \bar{e}_{c}-K_{c}>0$. However, $\beta<1$ has already been assumed since it measures marginal effectiveness to effort.

\section{Proof of Proposition 1}

Although the challenger is viable, the incumbent may deflect to reduce the financial resources available to him. Then, we have to show that the Protectionist lobby gains from supporting the challenger when the incumbent deflects. From Table 2, it must be

$$
\begin{aligned}
& \gamma_{I} \bar{P} G+(1-\bar{P}) G-C_{C}>\gamma_{I} \hat{P} G+\gamma_{C}(1-\hat{P}) G, \\
& G\left[\left(1-\gamma_{C}\right)(1-\hat{P})+\left(1-\gamma_{I}\right)(\hat{P}-\bar{P})\right]-C_{C}>0 .
\end{aligned}
$$

Being an interior solution, $\bar{P}<1, \hat{P}<1$, and $\hat{P}>\bar{P}$ and the square bracket in (A3) is positive. Therefore there exists a small enough $C_{C}$ such that the inequality holds for every

\footnotetext{
${ }^{28}$ Analogously, in our model $p$ satisfies $p v\left(H_{I}\right) H_{I}+C_{I}-K_{I}=0$. We do not need to consider a discontinuity for $p$ since we assume that the incumbent is always viable (i.e., $K_{I}=0$ ) so that $p=0$.
} 
possible $G$. From the point of view of the challenger, he will accept any $C_{C}$ because an advocacy contribution raises the expected utility of the candidate. If the challenger has to advocate a policy different from its optimal one, $C_{C}$ must cover $\bar{P} \pi$.

\section{Proof of Proposition 2}

Part i) is the result obtained in Proposition 1.

For part ii) to be valid, we must look at the condition that makes the Protectionist lobby not to offer an advocacy contribution to the challenger when he is not viable without advocacy contributions and the incumbent deflects. From Table 2, it must be

$$
\begin{aligned}
& \gamma_{I} \bar{P} G+(1-\bar{P}) G-C_{C}<\gamma_{I} \hat{P} G+\gamma_{C}(1-\hat{P}) G, \\
& G\left[\left(1-\gamma_{C}\right)(1-\hat{P})+\left(1-\gamma_{I}\right)(\hat{P}-\bar{P})\right]-C_{C}<0 .
\end{aligned}
$$

Note that differently from (A3), in (A4) $C_{C}$ is not arbitrary small but is an increasing function of $K_{C}$, which is assumed to be large enough to make the challenger not viable without advocacy contributions. Therefore, for not too large values of $G$ the inequality in (A4) is satisfied. When it is not satisfied, the Protectionist lobby asking the policy support to the challenger will prompt the incumbent to advocate a position as well, eliminating the optimality of deflection.

\section{References}

Alesina, A., \& Cukierman, A. (1990). The politics of ambiguity. Quarterly Journal of Economics, 105, 829850.

Alesina, A., \& Tabellini, G. (2005). Why do politicians delegate? NBER Working Paper, 11531.

Anderson, J. E. (1993). Domino dumping II: anti-dumping. Journal of International Economics, 35, 133150.

Anderson, J. E., \& Prusa, T. J. (2001a). Political market structure. NBER working paper, 8371.

Anderson, J. E., \& Prusa, T. J. (2001b). Strategic play in the market for influence. Mimeo, Boston College.

Aragones, E., \& Neeman, Z. (2000). Strategic ambiguity in electoral competition. Journal of Theoretical Politics, 12, 183-204.

Baron, D. P. (1989). Service-induced campaign contributions and the electoral equilibrium. Quarterly Journal of Economics, 104, 45-72.

Baron, D. P. (1994). Electoral competition with informed and uninformed voters. American Political Science Review, 88, 33-47.

Bernheim, D. B., \& Whinston, M. D. (1986). Menu auctions, resource allocation, and economic influence. Quarterly Journal of Economics, 101, 1-32.

Blonigen, B. A., \& Prusa, T. J. (2003). Antidumping. In K. E. Choi \& J. Harrigan (Eds.), Handbook of international trade. Oxford: Blackwell.

Destler, M. I. (1995). American trade politics. Washington DC: Institute for International Economics.

De Vault, J. M. (2002). Congressional dominance and the International Trade Commission. Public Choice, $110,1-22$.

Dixit, A., Grossman, G. M., \& Helpman, E. (1997). Common agency and coordination: general theory and application to government policy making. Journal of Political Economy, 105, 752-769.

Epstein, D., \& O’Halloran, S. (1999). Delegating powers. Cambridge: Cambridge University Press.

Finger, J. M., Hall, H. K., \& Nelson, D. R. (1982). The political economy of administered protection. American Economic Review, 72, 452-466.

Gallaway, M. P., Blonigen, B. A., \& Flynn, J. E. (1999). Welfare costs of the U.S. antidumping and countervailing duty laws. Journal of International Economics, 49, 211-244.

Gawande, K., \& Bandhopadhyay, U. (2000). Is protection for sale? A test of the Grossman-Helpman theory of endogenous protection. Review of Economics and Statistics, 82, 139-152.

Goldberg, P. K., \& Maggi, G. (1999). Protection for sale: an empirical investigation. American Economic Review, 89, 1135-1155. 
Grossman, G. M., \& Helpman, E. (1994). Protection for sale. American Economic Review, 84, 833-850.

Grossman, G. M., \& Helpman, E. (1996). Electoral competition and special interest politics. Review of Economic Studies, 63, 265-286.

Grossman, G. M., \& Helpman, E. (1999). Competing for endorsements. American Economic Review, 89, 501-524.

Magee, S. P., Brock, W. A., \& Young, L. (1989). Black holes tariffs and endogenous policy theory. Political economy in general equilibrium. Cambridge: Cambridge University Press.

Mayer, W. (1999). The political economy of administering trade laws. In J. Pigott \& A. Woodland (Eds.), International trade policy and the Pacific rim. London: Macmillan.

Shepsle, K. A. (1972). The strategy of ambiguity: uncertainty and electoral competition. American Political Science Review, 66, 555-568.

Shy, H. J. (1998). Possible instances of predatory pricing in recent US AD cases. In R. Z. Lawrence (Ed.), Brookings trade forum: 1998. Washington DC: Brookings.

Zanardi, M. (2004). Antidumping: what are the numbers to discuss at Doha? The World Economy, 27, 403433. 